\title{
DIRETRIZES CURRICULARES PARA A TEOLOGIA
}

José Antonio da Silva*

\section{RESUMO}

Este artigo tem como foco analisar o currículo da Teologia e o fato de ela ter se tornado um curso de suma importância em diversas universidades espalhadas pelo Brasil. A teologia fica inicialmente dispensada de uma diretriz curricular no próprio ato de aprovação do Conselho $\mathrm{Na}$ cional de Educação, muito embora reconhecida, no mesmo parecer, como área de conhecimento e, portanto, consolidada como resultado de uma tradição curricular.

Palavras-chave: teologia, currículo, Curso Superior.

\begin{abstract}
This article focuses on analyzing the curriculum of theology and its importance in the fact that theology has become a place of importance in various universities throughout the Brazil. The theology is initially given a guidance curriculum in the act of approval of the National Council of Education, although recognized in the same opinion, as an area of knowledge and therefore consolidated as a result of a traditional curriculum.
\end{abstract}

Key-words: theology, curriculum, Education Course.

\section{INTRODUÇÃO}

A teologia fica inicialmente dispensada de uma diretriz curricular no próprio ato de aprovação do Conselho Nacional de Educação, muito embora reconhecida, no mesmo parecer, como área de conhecimento e, portanto, consolidada como resultado de uma tradição curricular. Nesse sentido, surge o tema deste estudo, enfocando as diretrizes curriculares da teologia em seus cursos universitários no Brasil.

* Bacharel em Teologia pelo CES/JF e especialista em Ciências da Religião e Bioética. 


\section{DIRETRIZES CURRICULARES PARA A TEOLOGIA}

Inicialmente, Freitas (2006) revela que a razão para a afirmação acima é política, visando proteger as diversas orientações religiosas das ingerências do Estado. A ausência da teologia no cenário universitário brasileiro fez prevalecer o cuidado político sobre a coerência epistemológica, uma vez que uma área de conhecimento exige estatuto teórico e metodológico universal que transcenda as opções pessoais e grupais.

Entretanto, Freitas (2006) cita que, em se tratando de estatuto teórico, a teologia é portadora de uma tradição que antecede todas as áreas de conhecimento estatuídas ao longo da história e inseridas progressivamente na universidade. A própria instituição universitária teve de alguma forma, como pressuposto de sua organização acadêmica, o desenvolvimento teórico e metodológico da teologia nas escolas anteriores, uma vez que a escolástica produziu um método de estudo que serviu de referência didática para outros cursos universitários.

O que se nota é que as organizações curriculares são realizadas concomitantemente à formulação teórica e metodológica da teologia, princípio que vale para as demais áreas de conhecimento no contexto da universidade.

A teologia foi pensada e ensinada em um determinado contexto histórico, construindo modelos que visavam elucidar e justificar a vivência da fé nesse mesmo contexto. A essência do estatuto da teologia permanece sendo a relação entre fé e razão, nas múltiplas expressões que ambas adquirem ao longo da história do pensamento nos diversos contextos socioculturais.

Freitas (2006) revela que uma organização curricular dá-se como cruzamento de vários aspectos, envolvendo concepção de conhecimento, interesses políticos, contexto sociocultural e modelos de aprendizagem. $O$ currículo de teologia carrega camadas históricas de longa data, em todos esses aspectos, em sua estrutura e em seus componentes.

Conforme a autora acima, não há dúvida de que as diferentes concepções de teologia exerceram e exercem influência determinante em suas práticas ao longo da história do ensino teológico. A teologia descansa em seu estatuto mais íntimo de reflexão sobre a realidade a partir dos dados da fé, sobre uma concepção de conhecimento, anterior às concepções modernas que vincularam conhecimento à verificação empírica e domínio tecnológico. 
Freitas cita também que os cursos superiores das universidades modernas tiveram uma concepção e uma organização curriculares sempre mais vinculados à formação profissional. A titulação fica, quase sempre, destinada ao exercício de alguma profissão regulamentada legalmente pelos profissionais da categoria.

A teologia carrega em sua raiz e essência uma concepção clássica de conhecimento que estabelece a finalidade do conhecimento em si mesmo; busca-se o conhecimento porque conhecer é bom, portanto enobrece o espírito humano que se torna mais sábio. A dimensão da fé reforça, sobremaneira, essa concepção de raízes gregas, como expressa sinteticamente a ideia agostiniana de conhecer para amar.

Destaca-se que, embora a teologia forme o profissional, até o momento, com uma atuação mais restrita às igrejas, ela possui, antes de tudo, essa concepção de conhecimento que não vincula currículo à atuação no mercado, tanto quanto à filosofia; ao contrário, a atuação profissional será sempre uma decorrência de sua consistência e relevância para uma compreensão profunda da realidade, para a vivência social da fé e para a compreensão crítica dos próprios elementos da mesma fé. Nesse sentido, não há nenhuma exceção no exercício social da teologia que impeça a regulamentação e a organização de seus profissionais como nos demais cursos.

Freitas complementa afirmando que os primeiros pensadores cristãos se depararam com o problema teórico e prático da formulação teológica no contexto cultural helênico. A teologia nasce como esforço de pensar racionalmente a fé testemunhada nos textos bíblicos. O texto bíblico (que pede interpretação) e o contexto cultural (que oferece razão) encontram-se no esforço de intelecção da fé cristã. Em termos curriculares, trata-se de oferecer um estudo lógico e sistematizado dos textos bíblicos para contribuir com a comunidade cristã.

Assim, as escolas medievais vão construir, gradativamente, a distinção entre teologia bíblica e teologia especulativa, vindo a compor os instrumentos teóricos e didáticos da teologia-filosofia escolástica. O livro era o principal instrumento de estudo das universidades e, no caso das faculdades de teologia, o conjunto de livros da Bíblia.

A teologia vai se desenvolver, no seu viés especulativo, a partir do encontro entre os textos sagrados e a filosofia. Das considerações sobre 
o texto bíblico vai surgindo um conjunto de considerações especulativas deduzidas de princípios filosóficos, portanto externas ao texto bíblico, que dará origem às Sentenças, ou seja, a um sistema especulativo sobre temas teológicos extraídos dos Padres da Igreja e das definições conciliares.

$\mathrm{Na}$ verdade, quando surgem as universidades, a escolástica já havia construído um conjunto de abordagens sobre o texto bíblico que já adquirira vida própria como conteúdo a ser estudado e transmitido além dos livros da Bíblia. Desse modo, o currículo de teologia, nas suas origens universitárias, tem duas abordagens ou dois livros-texto: os estudos dos textos bíblicos e o livro das Sentenças elaborado pelo teólogo Pedro Lombardo.

Freitas (2006) cita que, de qualquer forma, essa tradição curricular sustenta-se tanto nos conteúdos internos da tradição cristã quanto nos elementos emprestados dos seus sistemas filosóficos contemporâneos. A lógica aristotélica vai fornecer uma injeção teórica, metodológica e curricular nos cursos de teologia das universidades, acentuando seu aspecto especulativo e sistemático.

Com essas premissas, a teologia será definida por Tomás de Aquino como ciência. Os conteúdos de teologia especulativa centram-se nas grandes questões de fé, sejam os herdados da tradição patrística e das antigas definições conciliares, sejam os comuns da práxis eclesial:

A reforma protestante vai rejeitar, ao menos no início, a utilização da filosofia nos estudos teológicos, bem como retirar dos currículos as temáticas ligadas à práxis eclesial católica. Trata-se de uma prática curricular mais enxuta, menos especulativa e que dará um impulso aos estudos bíblicos e, de modo particular, ao estudo das obras de Santo Agostinho (FREITAS, 2006, p. 181).

Ainda para Freitas (2006), a teologia pós-Reforma desdobrou-se, naturalmente, ao menos, em duas grandes práticas curriculares: a escolástica católica e as escolas reformadas, ambas resistentes ao pensamento moderno e cada vez mais fixadas em seus princípios internos e em suas funções eclesiais. A primeira vai consolidar-se como um sistema fixo a serviço da ortodoxia católica, a segunda vai produzir uma hermenêutica paradoxal centrada na literalidade do texto e, ao mesmo tempo, na liberdade do leitor.

Para a autora o resultado histórico posterior foi o fundamentalismo bíblico e as práticas religiosas emocionais. A escolástica sobrevive no 
pensamento oficial da Igreja Católica, ainda que na forma residual e oficial. O fundamentalismo e os pentecostalismos sobrevivem, frequentemente, como interpretações de cunho mais popular, resistindo ao processo racionalizador moderno, que continua pedindo o confronto entre a razão e a fé, agora no embate mais polarizado com as ciências.

Contudo, conforme Freitas (2006), a teologia moderna, gestada a partir do contato com as ciências modernas, despolarizou, gradativamente, a distinção rígida entre teologia católica e teologia reformada, sobretudo na esfera dos estudos bíblicos. Os teólogos do século $X X$, católicos e protestantes, formularam seus sistemas em diálogo com o contexto cultural e teórico configurado pelos tempos modernos; tomaram como objeto, problemáticas e temáticas modernas e, ao mesmo tempo, utilizaram em suas elaborações categorias teóricas da filosofia e das ciências modernas, o que significou atrevimento, quando não ruptura, com as suas referidas Igrejas.

Cita a autora que, nesse sentido, a Modernidade fez recrudescer as ortodoxias das Igrejas em seus princípios endógenos e aproximou os teólogos no campo comum da ousadia e da criatividade intelectual. A teologia, a partir do século $X X$, reforçou seu estatuto autônomo como exercício investigativo da razão sobre as fontes escriturísticas e sobre as próprias tradições eclesiais, abrindo possibilidades de novas práticas curriculares dentro de um quadro amplo e diversificado de sistemas teóricos e metodológicos.

Enfim, cita Freitas (2006) que em termos teóricos e metodológicos, as teologias modernas, em suas várias vertentes, agregaram à tradição teológica clássica novos modelos, assim como fez a filosofia a partir dos pensadores renascentistas, com seus inúmeros sistemas. Contudo, diferentemente da filosofia, a teologia ficou fora da universidade enquanto uma área de conhecimento não assimilada pela Modernidade em termos epistemológicos, políticos e curriculares. A universidade moderna assimilou a filosofia clássica como parte de uma grande tradição de conhecimento, garantindo-lhe cidadania, muito embora não se alinhasse à epistemologia moderna, marcada pela função tecnológica e profissional. A teologia moderna pode oferecer condições que induzam itinerários semelhantes ao da filosofia dentro das universidades atuais, ou seja, como uma tradição teórica que finca suas raízes na sólida tradição clássica e avança ao longo da história produzindo paradigmas diversos, numa relação dialética com os sistemas de pensamento mais amplos: 
É possível pensar, também, em um currículo comum para as Igrejas cristãs, tendo como fundo teórico e metodológico o acúmulo construído pela exegese bíblica, pela teologia sistemática, pela própria tradição patrística, assim como pelas disciplinas científicas tomadas como disciplinas auxiliares para os estudos teológicos (FREITAS, 2006, p. 183).

Freitas complementa afirmando que o meio acadêmico e a universidade olham para a teologia com respeito, por um lado, e com desconfiança e distanciamento, por outro. Podemos dizer que não há um diálogo constante e profícuo. A teologia é vista, em geral, como braço eclesiástico, como instrumento da Igreja ou, no mínimo, como poesia, agradável, bela, mas sem possibilidade de produção e resultados práticos. Longe das instituições públicas e laicas, a teologia, no meio acadêmico, tem se restringido às instituições confessionais de uma ou outra tradição religiosa. Na maioria das vezes, serve para a formação dos quadros eclesiais e, em menor número, procura um diálogo com as demais ciências. São poucas as universidades, em nosso país, que atribuem à teologia um estatuto científico.

Assim, a cidadania acadêmica da teologia virá com o avanço na qualidade da pesquisa e do ensino nas universidades e IES, tarefa que exigirá revisões teóricas e institucionais da prática teológica, bem como aprofundamentos que apontem caminhos para a sua consolidação enquanto área de saber.

Uma revisão primordial a ser feita é a do "escolasticismo teológico", de raízes longínquas e fortemente solidificadas na história das igrejas que, direcionando seus cursos para o consumo pastoral imediato, privilegiam a reprodução de fórmulas doutrinárias e práticas em prejuízo da investigação e da produção.

Esse escolasticismo adquire em nossos dias novas direções, tendendo, muitas vezes, para abordagens fundamentalistas e para um utilitarismo que privilegia formas de expressão comunicacional em detrimento da investigação regrada e sistemática dos conteúdos da fé (PASSOS, 2004, p. 117).

Assim, os novos caminhos na direção da cidadania acadêmica exigirão uma inserção plena dos cursos e disciplinas teológicas na dinâmica da pesquisa e do ensino dentro das instituições de ensino superior, criando mecanismos próprios de avaliação, além dos mecanismos formais do Ministério da Educação, delimitando com clareza a relevância social do estudo da 
teologia e construindo, ao mesmo tempo, sua visibilidade sociocultural, bem como a de seus profissionais.

\section{CONSIDERAÇÕES FINAIS}

Conclui-se, enfim, que a teologia se firma como ciência e como curso superior, presente em muitas cidades do Brasil e, em quase todas as faculdades, tem marcado presença positiva no curso superior brasileiro, ajudando a formar muitas mentes engrandecidas espiritualmente através de seu currículo, contendo muitas disciplinas formadoras de cidadãos, como a ética. Portanto, percebeu-se a importância cada vez maior da teologia, não somente como ciência, mas também como curso superior.

\section{REFERÊNCIAS BIBLIOGRÁFICAS}

BIDART, L. B. Espiritualidade, uma aplicação prática. 1. ed., Rio de Janeiro: Editora Gryphus, 2003.

CUNHA, L. A. A universidade temporã. Rio de Janeiro: Editora Civilização Brasileira S.A., 1980.

FERREIRA, M. M.; AMADO, J. (orgs.). Usos e Abusos da História Oral. Rio de Janeiro: Fundação Getúlio Vargas Editora, 1996.

HIGUET, E. A. A fé na reencarnação nos movimentos religiosos urbanos no Brasil. In: Ronaldo Sathler-Rosa. (Org.) Culturas e cristianismo. 1a. ed. São Paulo: Loyola, 1999, p. 127-140.

FOWLER, J. W. Estágios da Fé. São Leopoldo: Sinodal, 1992.

FREITAS, M. C. (org.). Teologia e sociedade: relevância e funções. São Paulo: Paulinas, 2006.

GOMES, A. M. A. (org.). Teologia: ciência e profissão (a identidade, a formação e o campo de atuação profissional do teólogo no Brasil). São Paulo: Fonte, 2005.

HORTAL, J. (S.J.). E haverá um só rebanho. História, doutrina e prática católica do Ecumenismo. São Paulo: Loyola, 1997.

PASSOS, J. D. A legitimidade da teologia na universidade: do político ao acadêmico. Estudos de Religião, v. 18, n. 27, jul/dez, 2004.

WRUBLEVSKI, S. M. Uma nova universalidade da teologia? Repensar, v. 2, n. 2, 2006. 